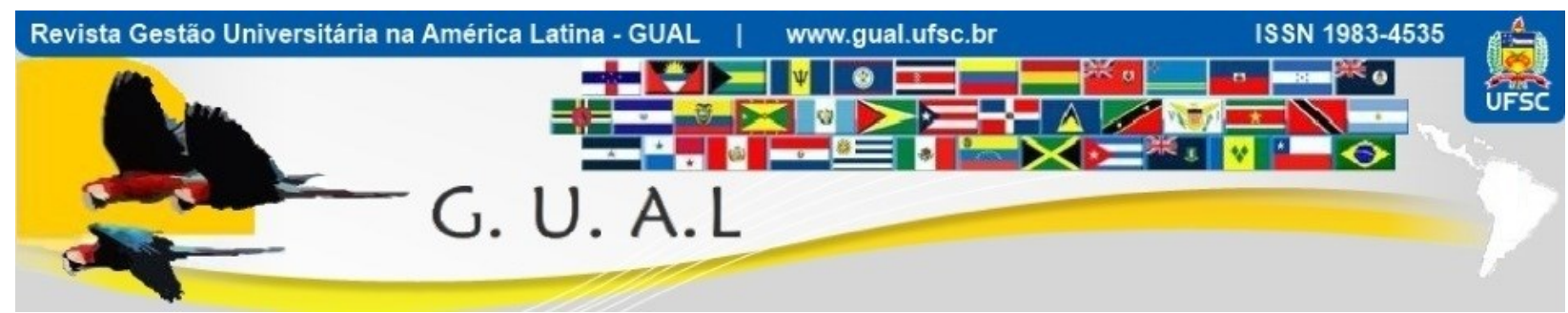

DOI: http://dx.doi.org/10.5007/1983-4535.2013v6n4p171

\title{
ATUAÇÃO DOS NÚCLEOS DE INOVAÇÃO TECNOLÓGICA NA PROMOÇÃO DO DESENVOLVIMENTO REGIONAL A PARTIR DA ABORDAGEM DA TRÍPLICE HÉLICE
}

\section{PERFORMANCE OF CENTERS OF TECHNOLOGICAL INNOVATION IN PROMOTING REGIONAL DEVELOPMENT FROM THE TRIPLE HELIX APPROACH}

\author{
Cassiane Chais, Mestranda \\ Universidade de Caxias do Sul - UCS \\ cassichais@gmail.com \\ Alexandra Mazzochi Scopel, Mestranda \\ Universidade de Caxias do Sul - UCS \\ alemscopel@gmail.com \\ Claralucia Prates Machado, Mestre \\ Universidade de Caxias do Sul - UCS \\ clarmachado9@gmail.com \\ Pelayo Munhoz Oléa, Doutor \\ Universidade de Caxias do Sul - UCS \\ pelayo.olea@gmail.com
}

Recebido em 29/novembro/2013

Aprovado em 29/novembro/2013

Sistema de Avaliação: Double Blind Review

Esta obra está sob uma Licença Creative Commons Atribuição-Uso. 


\title{
RESUMO
}

$\mathrm{Na}$ economia contemporânea o conhecimento, a inovação e a interação de universidade, empresa e governo tem relevância para seu desenvolvimento. A empresa concentra suas atividades produtivas na economia, o governo exerce papel regulamentador na garantia da estabilidade das interações dos atores desse processo. A universidade possui seu pilar no conhecimento, formando assim a Tríplice Hélice. Dessa forma, essa pesquisa buscou identificar quais são as relações já estabelecidas destes atores e quais as repercussões havidas neste contexto que integra universidades e empresas na busca de inovações tecnológicas. Para tanto, foi realizado um estudo de multicascos, análise de discurso para a avaliação das entrevistas em profundidade. Os achados deram conta que apesar de os atores envolvidos na Tríplice Hélice já terem um caminho construído existem muitos desafios a serem superados, principalmente no que tange ao hiato entre as universidades e o meio empresarial, bem como no ritmo de desenvolvimento dos projetos por parte das universidades.

Palavras-chave: Tríplice Hélice. Interação Universidade-Empresa. Núcleos de Inovação Tecnológica.

\begin{abstract}
In the contemporary knowledge economy, innovation and interaction of university, enterprise and government have relevance to development. The enterprise concentrates its productive activities in the economy, the government exerts regulatory role in ensuring the stability of the interactions of the actors of this process. The university has its mainstay in knowledge, thus forming a triple helix. Therefore, this research sought to identify which are existing relations of these actors and the repercussions in this context that integrates universities and enterprises in the pursuit of technological innovations. Thereby, a multi-case study, speech analysis for the evaluation of in-depth interviews was conducted. The findings have reported that although the actors involved in the triple helix having already built a way there are many challenges to overcome, especially in regard to the gap between universities and the business community as well as the pace of development projects by universities.
\end{abstract}

Keywords: Triple helix. University-enterprise interaction. Centers of technological innovation. 


\section{ATUAÇÃO DOS NÚCLEOS DE INOVAÇÃO TECNOLÓGICA NA PROMOÇÃO DO DESENVOLVIMENTO \\ REGIONAL A PARTIR DA ABORDAGEM DA TRÍPLICE HÉLICE \\ DOI: http://dx.doi.org/10.5007/1983-4535.2013v6n4p171}

\section{INTRODUÇÃO}

Em um ambiente econômico fundamentado no conhecimento e caracterizado pela existência de mercados dinâmicos e competitivos, emerge um elemento-chave para transpor os desafios, a busca constante pela inovação. Neste contexto, a abordagem denominada Tríplice Hélice, caracteriza a dinâmica da inovação, onde as relações se desenvolvem entre três esferas institucionais, envolvendo os atores: a universidade, a empresa e o governo (ETZKOWITZ; LEYDESDORFF, 2000).

A interação solidifica o contexto da Tríplice Hélice, onde governo, universidade e empresa se unem a favor do desenvolvimento e assim, as universidades cooperam com o setor empresarial ocasionando benefícios para ambos (DAGNINO, 2003). A inovação almeja auxiliar no crescimento e desenvolvimento econômico onde as ondas de mudanças tecnológicas são, na maioria das vezes, descontínuas, destruindo as velhas indústrias e gerando novas. O fenômeno chamado destruição criadora (SCHUMPETER (1942).

Cabe à universidade a tarefa de criar fontes de novos conhecimentos e tecnologias, estabelecer relações entre as empresas e os governos, criar novas áreas de atuação e conduzir os processos de mudança. Ao governo, compete promover o desenvolvimento econômico e social através de novas estruturas organizacionais, planos políticos com metas objetivas e voltadas para inovação e conhecimento. Às empresas cabe desenvolver produtos e serviços inovadores, promover a interação com os centros de transferência de tecnologia da comunidade científica e guiar os processos de mudança (PEREIRA NETO; GALINDO; CRUZ, 2004).

Dessa forma, este trabalho aborda a temática envolvendo a Tríplice Hélice e seus atores. Busca identificar quais as relações já estabelecidas e quais as repercussões contidas no contexto de integração entre os envolvidos na geração de inovações tecnológicas. O estudo objetivou também, analisar qual a visão dos gestores dos Nit's sobre a interação universidadeempresa, legislação da área, o papel dos Nit's na cultura da inovação nas universidades, qual a estratégia utilizada para atender pesquisadores e empresários.

Para tanto, o artigo estrutura-se em cinco partes: introdução, referencial teórico, onde aborda-se o modelo da Tríplice Hélice, descrevendo os atores envolvidos (universidade, empresa e governo). Posteriormente descreve a interação universidade-empresa, conceitua e caracteriza os núcleos de inovação tecnológica. Na sequência aborda a metodologia e a 
descrição de cada núcleo analisado. Logo após, apresenta-se a análise de dados e as considerações finais.

\section{REFERENCIAL TEÓRICO}

\subsection{MODELO DA TRÍPLICE HÉLICE}

Para uma economia que atualmente é baseada no conhecimento e na inovação a interação entre universidade, empresa e governo se torna destaque para seu crescimento. A empresa exerce atividades importantes na economia, sendo chefe do setor de produção. $\mathrm{O}$ governo exerce papel de destaque nas relações contratuais que garantem estabilidade para a interação e o intercâmbio entre os atores desse processo. A universidade por sua vez possui seu pilar no conhecimento, e sua vantagem competitiva perante as outras instituições são os estudantes, que possuem fluxo contínuo de ideias e projeções (ETZKOWITZ, 2009).

Dessa forma o modelo da Tríplice Hélice passou por vários caminhos, iniciando pelo modelo estatista, onde o governo controlava a universidade e as empresas. Na perspectiva proposta por este modelo o governo deve tomar a iniciativa da realização de projetos e geração de conhecimento e inovação na sociedade (Figura 1). Na sequência pelo modelo laissez-faire (Figura 2), onde empresas, academia e governo atuavam de forma separada, interagindo apenas o estritamente necessário. Nesses dois modelos sempre houve um grande esforço das universidades e das empresas para que a barreira da dependência com o governo fosse rompida, da mesma forma que a interdependência entre esses atores era considerada importante para o bom andamento da sociedade (ETZKOWITZ, 2009).

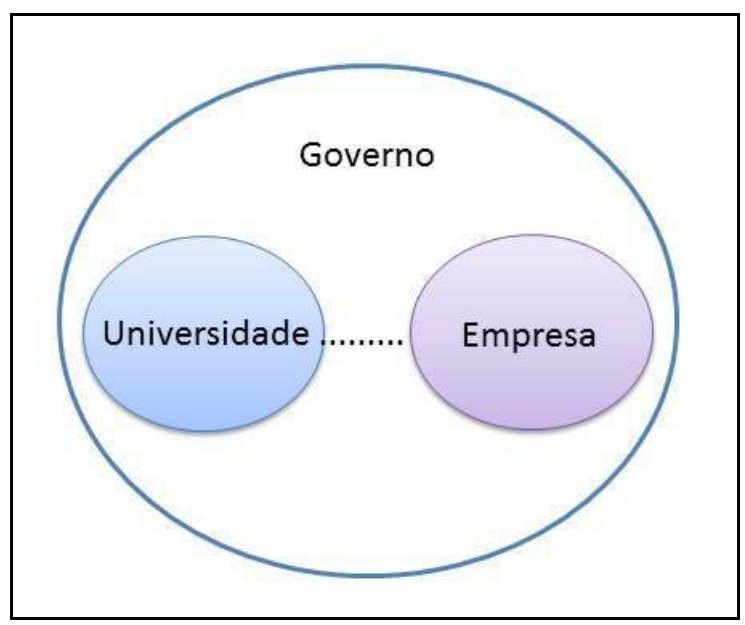

Figura 1 Modelo Estatista

Fonte: Adaptado de Etzkowitz; Leydesdorff, 2000 p. 111. 


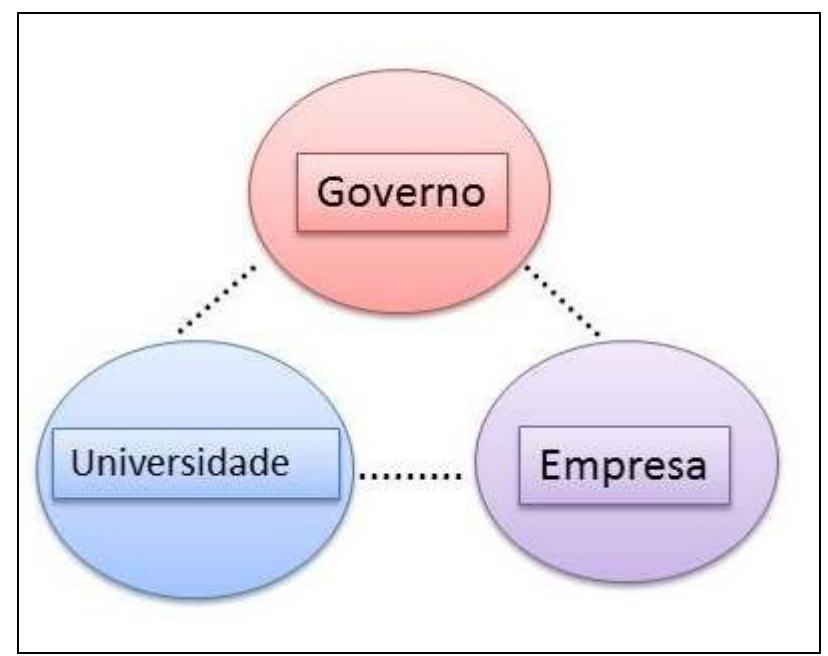

Figura 2 Modelo laissez-faire

Fonte: Adaptado de Etzkowitz; Leydesdorff, 2000 p. 111.

No modelo apresentado na figura 2, a universidade fornece pesquisa básica e conhecimentos tácitos que vão juntamente com o estudante para o mercado de trabalho. Para a empresa o papel é de aproveitar o conhecimento oriundo da universidade para assim criar novos produtos e elas devem operar sozinhas, obtendo relações com as demais somente de compra e venda, pois a colaboração é proibida. O governo, neste caso, tem um papel limitado agindo somente quando o mercado falhar (ETZKOWITZ, 2009).

No modelo da circulação da Hélice Tríplice, espera-se que cada uma das hélices possa se relacionar com as demais, formando assim redes de interações entre elas, demonstrando assim um desenvolvimento em espiral, conforme a figura 3. Dentro de cada uma das hélices devem ocorrer microcirculações, demonstrando o desempenho da atividade, objetivo principal daquele determinado setor, enquanto no exterior das hélices ocorrem as macrocirculações, evidenciando a interação entre as três hélices (ETZKOWITZ; LEYDESDORFF, 2000).

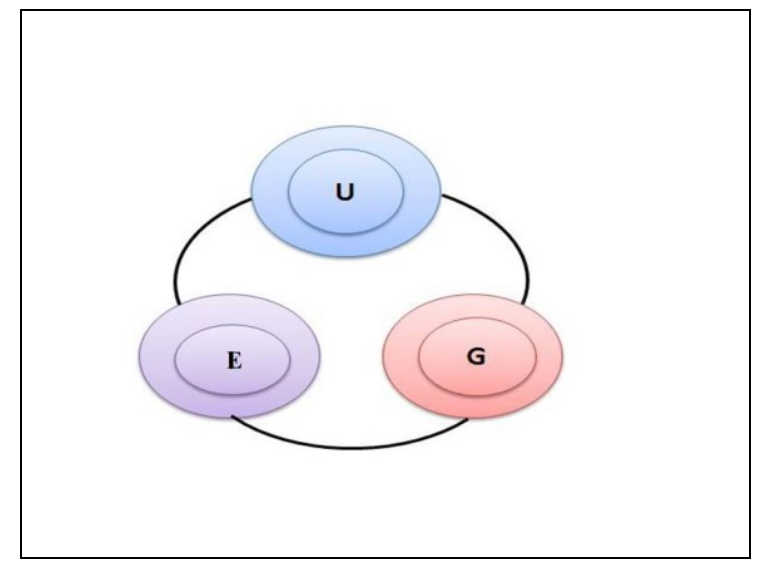

Figura 3 Modelo de circulação de indivíduos na Hélice Tríplice Fonte: Adaptado de Etzkowitz, (2009). 


\section{ATUAÇÃO DOS NÚCLEOS DE INOVAÇÃO TECNOLÓGICA NA PROMOÇÃO DO DESENVOLVIMENTO \\ REGIONAL A PARTIR DA ABORDAGEM DA TRÍPLICE HÉLICE \\ DOI: http://dx.doi.org/10.5007/1983-4535.2013v6n4p171}

$\mathrm{Na}$ sequência será relatado o papel de cada uma das hélices da Tríplice Hélice: Universidade, Empresa e Governo.

\subsubsection{Universidade}

Muitos discutem o real papel da universidade, após formar profissionais, para com a sociedade e o desenvolvimento econômico e social de uma região ou país. Para analisar isso são necessários alguns indicadores como, por exemplo, integração a projetos de pesquisas inovadoras, participação em startups modernas e de tecnologias avançadas e participação em empresas competitivas (FAVA-DE-MORAES, 2000).

Para Etzkowitz (2009), a nova missão da universidade é a de capitalização do conhecimento, conectando-se aos criadores e usuários do conhecimento para estabelecer-se como um ator por mérito, ou seja, é preciso produzir e fornecer desenvolvimento econômico para que possa ser reconhecida pela sociedade.

Um importante estudo coordenado e patrocinado pelo Banco de Boston, nos Estados Unidos no ano 2000 procurou identificar qual o nível de importância do (MIT) Massachusetts Institute of Tecnolgy através da produção dos seus alunos em pesquisas inovadoras que poderiam afetar a economia local, no estado e até mesmo no exterior. A pesquisa constatou que sozinhas as empresas criadas por alunos e pesquisadores do MIT constituem a $24^{\mathrm{a}}$ economia mundial. Isso significa, mais de 1 milhão de empregos gerados por cerca de 4 mil empresas com faturamento anual de mais de US\$ 230 bilhões. Todas elas são empresas de alto nível tecnológico e inovador (FAVA-DE-MORAES, 2000).

Nesse sentido, é preciso ter atenção com a qualidade do corpo docente de uma universidade, pois essa qualidade está positivamente relacionada com o envolvimento da academia no patenteamento, na capacidade empreendedora da universidade e de seus acadêmicos, dessa forma, os professores que possuem maior envolvimento empreendedor são aqueles que irão transmitir essa capacidade e motivação em sala de aula, formando assim jovens comprometidos com o desenvolvimento econômico de um país (PERKMANN; KING; PAVELIN, 2011).

Nem todas as universidades possuem um viés empreendedor, e seu foco não é na comercialização do conhecimento e inovações geradas por seus docentes e discentes e sim o ensino, mas há uma forte corrente mundial popularizando e transformando as instituições em universidades empreendedoras, deixando de ser aquelas universidades da Idade Média, consideradas comunidades isoladas de eruditos (ETZKOWITZ, 2009). 


\section{ATUAÇÃO DOS NÚCLEOS DE INOVAÇÃO TECNOLÓGICA NA PROMOÇÃO DO DESENVOLVIMENTO \\ REGIONAL A PARTIR DA ABORDAGEM DA TRÍPLICE HÉLICE \\ DOI: http://dx.doi.org/10.5007/1983-4535.2013v6n4p171}

\subsubsection{Empresa}

A transição de empresas industriais para empresas do conhecimento ocorre desde o século XIX, porém as ideias e os objetivos vêm se alterando. A partir do momento em que o conhecimento faz parte da produção e comercialização de bens, produtos e serviços, as organizações objetivam cultivar parcerias e convênios com outras áreas (ETZKOWITZ, 2009).

Essas organizações são vistas como um negócio, em que vendendo um produto se obtém a receita, até que cheguem ao sucesso ou ao fracasso. Mas para as empresas da Tríplice Hélice, isso pode se alterar, visto que essas organizações são baseadas na inovação organizacional e tecnológica que podem ocorrer em esferas municipais, estaduais e até mesmo internacionais, com a colaboração do governo e de institutos de pesquisa avançada (ETZKOWITZ, 2009).

As empresas tendem a criar parcerias com outras similares ao seu ramo. Na sequência com empresas maiores como, por exemplo, startups e centros de pesquisa ou universidades. Atualmente as grandes empresas transferiram unidades para os chamados parques tecnológicos ou parques científicos, instalados dentro das universidades e centros de pesquisa, para assim efetivar convênios, estar próximo ao conhecimento gerado pela pesquisa básica e aplicada, desenvolvida em grupos de pesquisa acadêmica, visando o licenciamento de novos produtos com potencial mercadológico (ETZKOWITZ, 2009).

Para Abdala; Calvosa; Batista (2009), a iniciativa privada deve ter como responsabilidade desenvolver produtos e serviços inovadores; promover a interação com a comunidade científica e liderar processos de mudança. Porém são visíveis as limitações presentes, como por exemplo, pouca capacidade de investimento para o desenvolvimento de novas tecnologias, e o despreparo acadêmico e tecnológico para a condução de pesquisas.

\subsubsection{Governo}

Segundo Fonseca (2001), ao governo cabe a função de prover recursos de forma correta para o apoio e incentivo às empresas e à iniciativa privada em prol do desenvolvimento social e econômico do país, já que empresas estão investindo consideravelmente pouco nesta área no nosso país.

Existem funções chamadas diretas e indiretas ao se tratar o papel do governo na Tríplice Hélice. Pode-se dizer que as políticas tecnológicas são indiretas, pois não atuam 


\section{ATUAÇÃO DOS NÚCLEOS DE INOVAÇÃO TECNOLÓGICA NA PROMOÇÃO DO DESENVOLVIMENTO \\ REGIONAL A PARTIR DA ABORDAGEM DA TRÍPLICE HÉLICE \\ DOI: http://dx.doi.org/10.5007/1983-4535.2013v6n4p171}

diretamente na criação das ideias e geração de conhecimento, e mesmo desta forma, são consideradas fundamentais para o desenvolvimento tecnológico de um país (FONSECA, 2001).

A criação de um ambiente econômico e político propício para a geração de conhecimento é fundamental para atrair investidores nacionais e internacionais. As instituições instáveis não geram confiança para os investidores, reduzindo a possibilidade de lucro sobre os investimentos realizados e isto vale tanto financeiramente quanto para os recursos humanos. Quanto maior a estabilidade política e econômica de um país menor será o risco de investir nele e maior será a chance de obter lucros (FONSECA, 2001).

De acordo com Fonseca (2001), não basta ter ideias, é preciso saber utilizá-las, e para isso, mais uma vez o governo possui papel importante, na medida em que investe na criação de centros de pesquisa, parques tecnológicos, e na educação, geração de capital humano.

As relações entre empresa e universidade estão aumentando em diversos países em diferentes estágios de desenvolvimento e diferentes valores culturais. E neste cenário, é vital que cada ator possa desenvolver seu papel melhorando assim o estímulo ao processo de geração de conhecimento, na mobilização da sociedade para uma cultura de inovação, envolvendo empresas e universidades (ETZKOWITZ, et al. 2000).

\subsection{INTERAÇÃO UNIVERSIDADE - EMPRESA}

O processo de interação universidade empresa inicia na medida em que o setor produtivo necessita de uma nova tecnologia, ou até mesmo quando o setor científico produz ou gera novos conhecimentos que possuem aplicações práticas, surgindo assim, a interação entre estes setores para a promoção da inovação tecnológica (CUNHA; FISCHMANN, 2003).

A interação dos dois atores do processo se tornou primordial para a saúde econômica de um país. E para que a interação ocorra, o sistema produtivo necessita estar capacitado tecnologicamente, isso inclui uma parceria e cooperação do governo para com as empresas e universidades (MOTA, 1999).

Para que a inovação tecnológica aconteça está sendo necessário um conhecimento científico mais denso e com isso a interação entre universidade-empresa é uma das alternativas mais confiáveis. Com a interação se torna possível a união do conhecimento gerado na universidade com a prática e experiência mercadológica das organizações, uma parceria que pode modernizar o parque industrial do país (CUNHA; FISCHMANN, 2003). 


\section{ATUAÇÃO DOS NÚCLEOS DE INOVAÇÃO TECNOLÓGICA NA PROMOÇÃO DO DESENVOLVIMENTO \\ REGIONAL A PARTIR DA ABORDAGEM DA TRÍPLICE HÉLICE \\ DOI: http://dx.doi.org/10.5007/1983-4535.2013v6n4p171}

De acordo com Ripper Filho (1994), interações formais exigem muito esforço de cada uma das partes para que possa dar certo, visto que cada uma possui suas prioridades e investimentos. Dessa forma, a relação só será interessante para as partes se gerarem vantagens muito maiores que seus esforços. Por exemplo: para a universidade deve haver a compreensão de que a interação contribui para a formação dos profissionais, objetivo maior dessa instituição. E a empresa ou organização, por sua vez, objetiva lucros e com isso precisa perceber diretamente essa contribuição (RIPPER FILHO, 1994).

Segundo Etzkowitz (2009), a universidade deve assumir uma postura mais empreendedora, buscando encontrar pesquisas realizadas dentro do contexto da academia que podem servir como potenciais tecnológicos e serem colocados em prática, tornando-se assim, uma inovação. Que tem como premissa básica o crescimento econômico, onde as ondas de mudanças tecnológicas são descontínuas, destroem as velhas indústrias e geram novas SCHUMPETER (1942).

Essa postura empreendedora que a universidade deve possuir pode ser percebida quando ela se envolve com educação empreendedora, com a transferência de tecnologia e com a formação de novas empresas pelo processo de incubação. Essa cultura empreendedora poderá atuar como incentivadora para o corpo docente de uma universidade, que tradicionalmente possui foco intelectual para suas pesquisas, passando a criar um olhar voltado para um novo potencial, o mercadológico (ETZKOWITZ, 2009).

Com essa postura inovadora a universidade passa a perceber que necessita de agentes que atuem na relação entre o empresário e as intenções da universidade durante a parceria efetuada. Desse tipo de intervenção surgiram os escritórios de transferência de tecnologia, justamente para que neste setor possam estar profissionais preparados para realizar e efetivar a interação (CUNHA; FISCHMANN, 2003).

\subsection{NÚCLEOS DE INOVAÇÃO TECNOLÓGICA (NIT’S)}

Em 1984 iniciaram as ações de Programas de Apoio ao Desenvolvimento Científico e Tecnológico - PADCT, vinculados ao Ministério da Ciência e Tecnologia - MCT. Este programa compreendeu diversas áreas para o desenvolvimento da nação, dentre elas a propriedade industrial (LIMA, 2010).

Em 1998, iniciou-se uma discussão sobre a importância da Propriedade Industrial para o desenvolvimento econômico do país, principalmente em relação à internacionalização da 


\section{ATUAÇÃO DOS NÚCLEOS DE INOVAÇÃO TECNOLÓGICA NA PROMOÇÃO DO DESENVOLVIMENTO \\ REGIONAL A PARTIR DA ABORDAGEM DA TRÍPLICE HÉLICE \\ DOI: http://dx.doi.org/10.5007/1983-4535.2013v6n4p171}

economia. Nessa década, ficou evidente a falta de uma legislação nacional que contemplasse e norteasse as ações dessa área em desenvolvimento, pois os Nit's possuíam nomenclaturas diferentes, ações desencontradas e totalmente sem foco. Essa situação foi crucial para a criação da Lei Nacional de Inovação em 2004 (LIMA, 2010).

A Lei da Inovação, no 10.793 de 02 de dezembro de 2004, define Nit como Núcleo de Inovação Tecnológica ou órgão constituído por uma ou mais ICT (Instituição Científica e Tecnológica), com a finalidade de gerir sua política de inovação. Os Nit’s são responsáveis também, por acompanhar os processos de desenvolvimento da pesquisa à inovação e pela promoção de parcerias entre a academia e o setor privado (CASTRO; SOUZA, 2012).

Em sua maioria, os núcleos criados no país foram oficializados após a publicação da Lei da Inovação, que passou a exigir a existência desses núcleos nas ICT’s. Porém, algumas universidades já possuíam em sua estrutura setores de apoio à gestão de projetos e processos de inovação tecnológica, e talvez isso possa explicar o fato de alguns núcleos serem mais profissionalizados do que os demais (CASTRO; SOUZA, 2012).

De acordo com Castro e Souza (2012), a concentração de núcleos de inovação tecnológica se dá nas Regiões Sul e Sudeste do Brasil. A pesquisa realizada pelos autores, contatou 78 núcleos brasileiros, e destes a maioria não possuía número maior do que 10 depósitos de patentes, e muitos deles sequer realizaram transferência de tecnologia, que é uma das atividades do Nit, pois a intenção de patentear surge para que se possa auferir lucros na transferência da tecnologia da universidade para as empresas, gerando assim inovação que proporcione retorno econômico e gere impacto na economia.

As atividades vinculadas aos Nit's dentro da estrutura das ICT's são relacionadas ao zelo pela política institucional e o estímulo à cultura da inovação pela proteção da propriedade intelectual, licenciamento de patentes, gerenciamento de contratos de transferência de tecnologia, a interação entre universidades e empresas, realização de eventos que estimulem e criem um ambiente propício para a disseminação da inovação na universidade, e o auxílio aos pesquisadores na captação de recursos para a inovação entre outras atividades (MAIS, et al. 2008).

\section{METODOLOGIA}

Essa pesquisa caracterizou-se por ser um estudo de multicasos. Segundo Gil (2010), é uma modalidade de pesquisa muito utilizada nas ciências sociais e biomédicas, caracterizada 


\section{ATUAÇÃO DOS NÚCLEOS DE INOVAÇÃO TECNOLÓGICA NA PROMOÇÃO DO DESENVOLVIMENTO \\ REGIONAL A PARTIR DA ABORDAGEM DA TRÍPLICE HÉLICE \\ DOI: http://dx.doi.org/10.5007/1983-4535.2013v6n4p171}

por um estudo amplo e detalhado de poucos objetos, para que possa ser uma pesquisa rica em detalhes e conhecimento do assunto abordado.

Segundo Yin (2005) é fundamental para um bom resultado o estudo de mais de um caso, para que assim sejam possíveis comparações entre ambos validando e tornando mais confiável a pesquisa.

A abordagem a ser utilizada será de um estudo qualitativo. Nessa abordagem o pesquisador é quem procura compreender a questão a ser estudada, e seus fenômenos a partir do seu entendimento sobre os fatos ocorridos ou relatados (NEVES, 1996) as questões utilizadas na entrevista são apenas norteadoras, não sendo necessária sua execução rígida, a estrutura serve apenas como apoio para o momento (SILVA; GODOI; BANDEIRA-DEMELLO, 2006).

O procedimento utilizado para exame do conteúdo das entrevistas será o de análise de discurso. Nesta técnica o discurso possui uma conotação onde a linguagem utilizada é compreendida em seu contexto histórico e social, isto é, porque traz em si os valores e a história social dos grupos que está inserida. Ela procura compreender e extrair sentidos dos textos, onde o discurso é efeito de sentidos entre locutores (ORLANDI, 2012).

Em função dos vários níveis de estruturação que a entrevista pode obter, existem várias classificações, como por exemplo: entrevistas informais, focalizadas, por pautas ou semiestruturadas e formalizadas. Este estudo utilizou a entrevista semiestruturada. As entrevistas por pautas ou semiestruturadas permitem ao entrevistador se guiar por uma relação de temas ou pontos importantes a serem questionados ao entrevistado (GIL, 1999).

Para esta pesquisa, foram realizadas entrevistas com os gestores dos Nit's - Núcleos de Inovação Tecnológica de três universidades particulares do Estado do Rio Grande do Sul, Brasil. As entrevistas obtiveram tempo de duração de aproximadamente 45 minutos, dependendo de cada entrevistado, sendo registradas em fichários dos pesquisadores. Os núcleos entrevistados estão denominados no texto como núcleo $\mathrm{A}$, núcleo $\mathrm{B}$ e núcleo $\mathrm{C}$.

O objetivo das entrevistas foi analisar qual a visão dos gestores dos Nit's sobre a interação universidade-empresa, legislação da área, o papel do Nit na cultura da inovação nas universidades, qual a estratégia utilizada para atender pesquisadores e empresários, que possuem visões diferenciadas, um voltado para pesquisa, e outro para o mercado. 


\section{ATUAÇÃO DOS NÚCLEOS DE INOVAÇÃO TECNOLÓGICA NA PROMOÇÃO DO DESENVOLVIMENTO \\ REGIONAL A PARTIR DA ABORDAGEM DA TRÍPLICE HÉLICE \\ DOI: http://dx.doi.org/10.5007/1983-4535.2013v6n4p171}

\section{NÚCLEO - A}

O núcleo A foi criado em 20 de março de 2006, pelo Conselho Diretor da Fundação de Ensino. Vinculado à Vice-Reitoria de Pesquisa e Pós-Graduação, tem como função primordial promover a inovação e a transferência de tecnologia. Esses dois processos estão baseados no potencial da instituição em produzir inovação, principalmente a partir dos mais de 300 projetos de pesquisa e dos cursos de graduação e pós-graduação (lato e stricto sensu). Além disso, está localizado em uma região vocacionada para a produção industrial, e que demanda inovações tecnológicas que agreguem valor e permitam ganhos de mercado. Aproximar quem gera conhecimento (academia) de quem produz bens (empresas) é fundamental para esse processo.

O núcleo atua hoje, em quatro áreas, são elas: Prospecção, captação e gestão de recursos para projetos de inovação, principalmente junto aos órgãos públicos de fomento à ciência e tecnologia, em projetos isolados da instituição ou em projetos associados a outras empresas e instituições. Transferência de tecnologia, através do licenciamento de patentes, softwares e cultivares, bem como pela transferência de know-how e difusão tecnológica. Gestão da propriedade intelectual, com o acompanhamento das tecnologias desde a fase de projeto até a fase de registro e certificação, além da elaboração de instrumentos para a valoração e licenciamento. Interação universidade-empresas, atendendo demandas específicas das empresas no desenvolvimento de inovações e soluções tecnológicas e de gestão, e buscando patrocínios para projetos de pesquisa com potencial de mercado.

Fazem parte da equipe do núcleo, duas agentes de inovação e uma agente de propriedade intelectual assessorada por um escritório. O gestor do Nit A participa ativamente da Rede Gaúcha de Propriedade Intelectual, e coordenou projetos como o Extensão Produtiva e Inovação, projeto do Governo Estadual em parceria com a universidade, que atendeu em 2012, aproximadamente 140 empresas da Região Norte do Estado do Rio Grande do Sul.

\section{NÚCLEO - B}

Criado em 1998, o núcleo $\mathrm{B}$ possui a finalidade de promover e intermediar negociações entre a instituição e a comunidade onde atua em todo o processo. Desde o suporte aos professores até o registro nos órgãos devidos, como também empenha-se na tentativa de comercialização dos ativos. A partir de 2010 o núcleo B passou a atuar com dois setores, um especializado em trabalhar com as questões legais que envolvem todo o 
arcabouço legal de propriedade intelectual e a outra esfera do núcleo B atua como agência de projetos que engloba o atendimento e gerenciamento de projetos na instituição, proporcionando o suporte administrativo necessário para o desenvolvimento de projetos PD\&I.

O núcleo B possui seu foco nas ações de transferência do conhecimento produzidos na universidade, gerenciar o portfólio de ativos intangíveis da universidade e trabalhar com questões legais que envolvem todo o arcabouço legal de propriedade intelectual.

\section{NÚCLEO - C}

O núcleo $\mathrm{C}$ foi criado a partir da necessidade de proteger o patrimônio intelectual da universidade e promover a transferência dos resultados de pesquisa ao setor produtivo, buscando fortalecer e ampliar a inserção na sociedade.

Através do licenciamento ou transferência de know-how, o núcleo $\mathrm{C}$ tem a função de realizar a avaliação econômica da tecnologia que será licenciada ou transferida, através de uma análise de mercado nacional e internacional. Através de contatos com os pesquisadores, o núcleo $\mathrm{C}$ busca captar potenciais licenciantes e/ou parceiros interessados no desenvolvimento da tecnologia em escala industrial, participando das negociações com o setor empresarial, promovendo reuniões de negociação entre a universidade e a empresa interessada, atuando ainda nas áreas de pesquisa e desenvolvimento e registro da propriedade intelectual.

O núcleo C é o setor responsável dentro da universidade pela gestão do seu patrimônio intelectual sendo ligado a Pró-Reitoria de Pesquisa, Inovação e Desenvolvimento o núcleo foi criado em março de 2005 para promover a aplicação prática dos resultados da pesquisa universitária para o benefício público, através do licenciamento de ativos intangíveis e outras formas de transferência de tecnologia.

\section{ANÁLISE DOS DADOS}

A interação universidade-empresa no núcleo A ocorre de diversas formas. Principalmente intermediando serviços tecnológicos específicos e por demanda dos empresários, com foco em resolução de problemas tecnológicos e de fabricação no desenvolvimento parcial de novos produtos e também através da validação de produtos desenvolvidos por empresas e testados e avaliados pelos pesquisadores da universidade. 


\section{ATUAÇÃO DOS NÚCLEOS DE INOVAÇÃO TECNOLÓGICA NA PROMOÇÃO DO DESENVOLVIMENTO \\ REGIONAL A PARTIR DA ABORDAGEM DA TRÍPLICE HÉLICE \\ DOI: http://dx.doi.org/10.5007/1983-4535.2013v6n4p171}

De acordo com Motta (1999), as universidades necessitam estar conectadas tanto com o setor produtivo, bem como com o governo, e isso se percebe no núcleo A pelo vínculo com projetos específicos, como o projeto Extensão Produtiva e Inovação, que atua com o apoio governamental estadual, que atende em forma de consultorias empresas da região de abrangência da universidade. Bem como através da captação de recursos através de editais, chamadas e subvenção tanto estadual como federal.

De acordo com o Gestor do núcleo A um entrave importante a ser vencido em sua instituição e que se percebe claramente ser uma dificuldade encontrada por todos os Nit's entrevistados, é a falta de carga horária destinada à pesquisa, ou a projetos com viés mercadológico. As universidades ainda possuem seus professores com a carga horária preenchida com sala de aula, orientação, e projetos de pesquisa básica, sendo muito complicado desenvolver projetos com empresas, que demandam mais tempo e comprometimento para o cumprimento das metas. Isso colabora para que a universidade seja vista como "lenta e demorada", tempo que o mercado não pode esperar. Segundo a Coordenadora do núcleo $\mathrm{C}$, um dos maiores desafios é mudar o ritmo lento das universidades, pois segundo ela, somente assim se poderá diminuir o gap existente entre as partes.

É possível perceber nas entrevistas realizadas, que os Nit's têm consciência da importância da interação para o desenvolvimento local, regional e nacional. Seja na criação de áreas de excelência, ao cumprir o papel da universidade em desenvolver e capacitar seus alunos para o mercado, tanto em ensino, pesquisa e extensão, conforme compreende o núcleo $\mathrm{B}$, ou até mesmo na própria geração de novos produtos em conjunto com o setor produtivo atuando de forma direta no desenvolvimento da nação, como define o gestor do núcleo A.

Na maioria dos Nit's em questão, a estrutura é boa, pois eles atuam diretamente na captação desses recursos, e como através da Lei de Inovação (2004), os Nit's deveriam ser criados e estruturados, o governo disponibilizou recursos tanto para a estrutura e equipamentos como para a formação em cursos e viagens técnicas.

Percebe-se também que a estrutura de profissionais nos Nit's é formada por físicos, administradores, secretárias executivas, advogados e não mais por estagiários. Da mesma forma essa captação é realizada para os projetos da universidade em parceria com as empresas, pois de acordo com o núcleo A, o governo está cumprindo com seu papel de disponibilizar recursos e instaurar a legislação a ser seguida. 


\section{ATUAÇÃO DOS NÚCLEOS DE INOVAÇÃO TECNOLÓGICA NA PROMOÇÃO DO DESENVOLVIMENTO \\ REGIONAL A PARTIR DA ABORDAGEM DA TRÍPLICE HÉLICE \\ DOI: http://dx.doi.org/10.5007/1983-4535.2013v6n4p171}

Porém para o núcleo $\mathrm{C}$ o entendimento é de que sim, existem muitos recursos a disposição, porém apresentados de forma equivocada, pois tais recursos ofertados pelo governo, na maioria das vezes não contemplam a necessidade da comunidade. Segundo a Coordenadora do núcleo $\mathrm{C}$, a grande massa de recursos federais é destinada à pesquisa básica, sendo que a pesquisa aplicada perfaz a maior necessidade das comunidades empresariais locais.

Quanto a legislação existente no país há certa divergência entre as opiniões. O gestor do núcleo A observa que as bases já estão constituídas e que agora falta a difusão dessas ideias e operacionalização do que as legislações preveem, principalmente na criação de mecanismos que as empresas e instituições possam utilizar os recursos existentes. De acordo com a coordenadora do núcleo $\mathrm{C}$ o governo já fez o seu papel, cabe agora as universidades estabelecerem o estreitamento de relações com o meio empresarial, é necessário segundo ela "falar a mesma linguagem” para que os projetos tenham fluência. Já para o núcleo B algumas alterações são importantes, pois a evolução na área ocorre de forma muito ágil, e a legislação acaba ficando desatualizada. Questionados sobre a criação do Código Nacional de Ciência Tecnologia e Inovação Projeto de Lei $n^{\circ}$ 2.177/2011, nenhum dos gestores informou estar acompanhando as discussões no Congresso Nacional.

Outra divergência encontrada é a legislação interna nas IES, como por exemplo, o núcleo $\mathrm{B}$ e o núcleo $\mathrm{C}$ já possuem instrução normativa sobre a proteção intelectual produzida na universidade desde o ano de 2007, enquanto o núcleo A ainda não possui essa legislação aprovada, embora de acordo com o Gestor do Nit, a minuta da normativa já tenha sido encaminhada para a Reitoria da universidade no ano de 2010.

No núcleo B foram efetivadas duas transferências de tecnologias para empresas, já no núcleo A nenhuma transferência foi realizada. Quanto ao núcleo $\mathrm{C}$, foram transferidas várias tecnologias e muitos processos ainda se encontram em andamento.

Foi possível identificar que os Nit's entrevistados investem em cursos, palestras, congressos tanto para que possam auxiliar no entendimento da comunidade acadêmica e empresarial, bem como em capacitação para seus funcionários sobre os temas relacionados à inovação, buscando assim, ampliar essa cultura em suas instituições. Neste sentido, o núcleo C desenvolveu um projeto voltado para os cursos de graduação onde são ofertadas aos alunos disciplinas transversais sobre a gestão da inovação. 


\section{ATUAÇÃO DOS NÚCLEOS DE INOVAÇÃO TECNOLÓGICA NA PROMOÇÃO DO DESENVOLVIMENTO \\ REGIONAL A PARTIR DA ABORDAGEM DA TRÍPLICE HÉLICE \\ DOI: http://dx.doi.org/10.5007/1983-4535.2013v6n4p171}

\section{CONSIDERAÇÕES FINAIS}

Após a realização das entrevistas e das análises dos resultados obtidos, conclui-se que os Nit's estudados possuem interação com as empresas de suas regiões, através de serviços tecnológicos, laboratoriais, desenvolvimento parciais e de novos produtos, e a validação de produtos inventados pelas empresas e certificados pelos pesquisadores das universidades. Essa interação afeta diretamente a característica da universidade que passa a demonstrar sua capacidade de ser empreendedora e inovadora.

Ficou evidenciado, a partir das entrevistas, que o caminho para um melhor envolvimento do corpo docente das IES abordadas é rever a carga horária destinada aos pesquisadores envolvidos em projetos de inovação e em convênios com empresas, pois atualmente, esses pesquisadores encontram-se com muitas horas em sala de aula e orientações, supervisões e pesquisa básica (que na maioria das vezes não possui grau de invenção) e não conseguem assumir o papel de pesquisador empreendedor, e dedicar-se às pesquisas aplicadas que geram inovação.

$\mathrm{O}$ apoio da gestão dessas instituições de ensino é fundamental, na medida em que a pesquisa detecta que ainda existem Nit's que não possuem uma legislação própria para a propriedade intelectual gerada na universidade. É preciso que a gestão universitária seja feita com entendimento sobre a importância que a inovação possui no desenvolvimento e geração de conhecimento e agilidade na elaboração de convênios, contratos e transferências entre os atores, conforme figura 4.

Esse é um diferencial importante que a universidade pode apresentar na formação de seus alunos e na capacitação de seu corpo docente, que envolvidos com esses processos de geração de inovação geram retorno econômico e impacto na economia.

Os Nit's compreendem o seu papel na disseminação da cultura da inovação e atuam diretamente na promoção de eventos que auxiliem no entendimento dos temas bem como estão em constante capacitação para realizar de forma profissional a interação desses atores e a transferência tecnológica propriamente dita.

Perfazendo este caminho, observa-se claramente a importância da Tríplice Hélice no desenvolvimento de uma região ou até mesmo de uma nação. Pois através do auxílio do governo no incentivo e geração de conhecimento na universidade através da pesquisa aplicada que gera a invenção, transferindo para as empresas (inovação), difundindo para o mercado 
consumidor, essa inovação pode fazer com que ocorram movimentações na economia e consequentemente o desenvolvimento tecnológico e econômico.

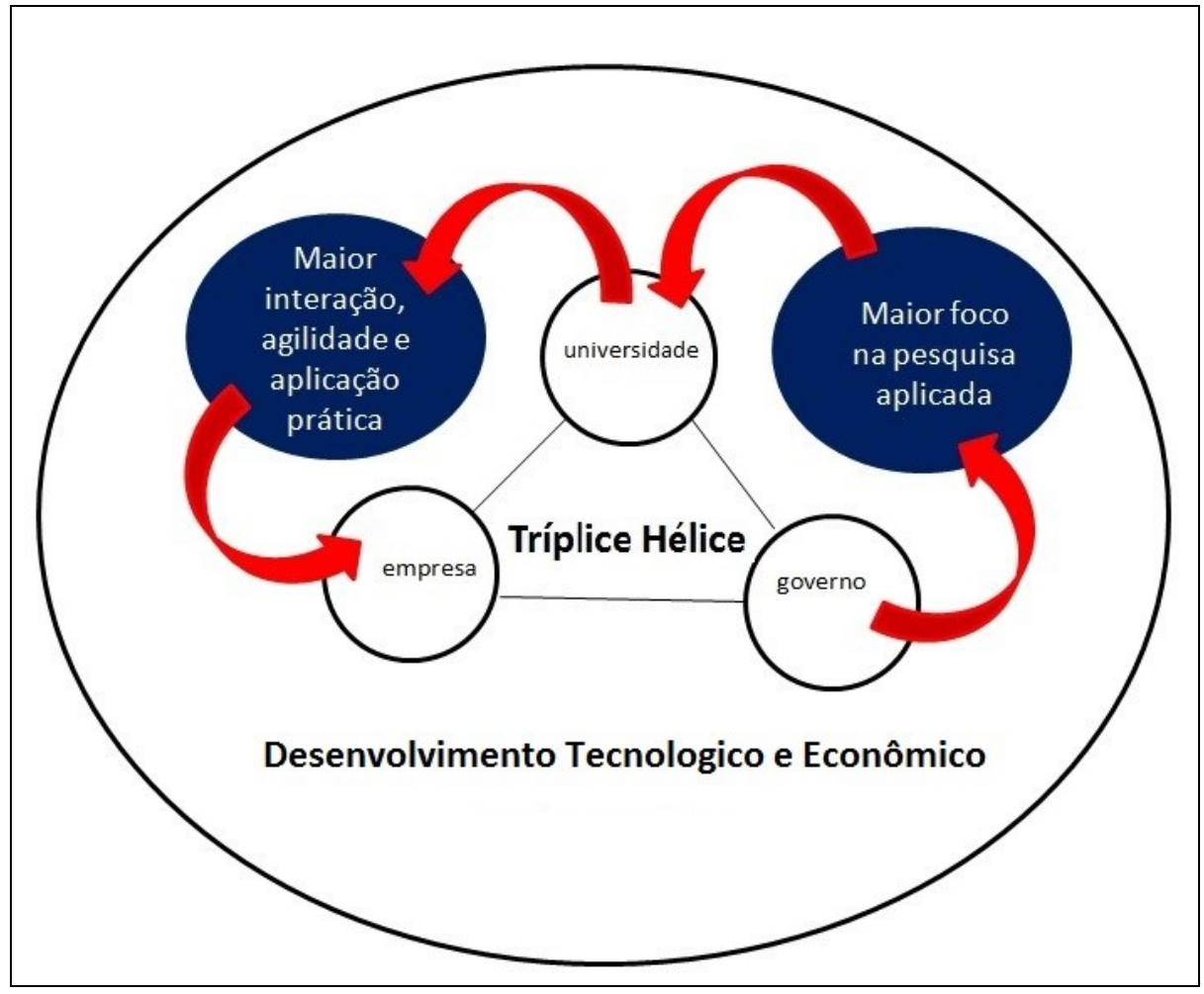

Figura 4 Conclusão do artigo.

Fonte: As autoras.

\section{REFERÊNCIAS}

ABDALA, Márcio Moutinho; CALVOSA, Marcello Vinícius Dória; BATISTA, Luciene Gouveia. Hélice Tríplice no Brasil: Um ensaio teórico acerca dos benefícios da entrada da Universidade nas parcerias Estatais. Disponível em:

$<$ http://www.fsma.edu.br/cadernos/Artigos/Cadernos_3_artigo_3.pdf $>$. Acesso dia 09 de dez. 2012.

BRASIL. Lei nº 10973, Lei da Inovação. 2004.

CARAYOL, Nicolas. Objectives, agreements and matching in scienceindustrycollaborations: reassembling the pieces of the puzzle. Research Policy, n.32, p.887908, 2003.

CASTRO, Biancca Scarpeline de Castro; SOUZA, Gustavo Costa de. O papel dos Núcleos de Inovação Tecnológica (Nit’s) nas Universidades brasileiras. Liinc em Revista, Rio de Janeiro: v. 8 n.1 Mar.2012.

CUNHA, Neila Viana da; FISCHMAN, Adalberto. Alternativas de ações estratégicas para promover a interação universidade-empresa através dos escritórios de transferência de 
tecnologia. Anales del Seminario Latinoiberoamericano de Gestión Tecnológica, Cidade do México, México, 2003.

DAGNINO, Renato. A relação universidade-empresa no Brasil e o argumento da hélice tripla. Rio de Janeiro. Revista Brasileira de Inovação, v. 2, n. 2, p.267-307, julho/dez, 2003.

ETZKOWITZ, Henry. Hélice Tríplice. Universidade-Indústria-Governo: Inovação em Movimento. Porto Alegre: EDIPUCRS, 2009.

ETZKOWITZ, Henry; LEYDESDORFF, Loet. The dynamics of innovation: from National Systems and "Mode 2" to a Triple Helix of university - industry government relations, Research Policy, n. 29, p. 109-123, 2000.

ETZKOWITZ, Henry. et al. The Future of University and the University of the Future: evolution of ivory tower to entrepreneurial paradigm. Research Policy, n. 29, p. 313-330, 2000 .

FAVA-DE-MORAES, Flávio. Universidade, inovação e impacto socioeconômico. São Paulo Perspec., São Paulo, v. 14, n. 3, jul. 2000 . Disponível em $<$ http://www.scielo.br/scielo.php?script=sci_arttext\&pid=S0102$88392000000300003 \& \operatorname{lng}=$ pt\&nrm=iso $>$. Acesso dia 25 jul. 2012.

FONSECA, Renato. Inovação tecnológica e o papel do governo. Parcerias estratégicas. v. 6. n. 13, p. 64-79, 2001.

GIL, Antonio Carlos. Como Elaborar Projetos de Pesquisa. 5. ed. São Paulo: Atlas, 2010.

GIL, Antonio Carlos. Métodos e Técnicas de Pesquisa Social. 5. ed. São Paulo: Atlas, 1999.

LIMA, Francisca Dantas. O Papel dos NITs nas ICTs e as ações do Fortec. Fórum Nacional de Gestores de Inovação e Transferência de Tecnologia - Fortec. Terezina, Piauí, 2010.

MAIS, Ilisangela; CARVALHO, Luciano Castro de; MACHADO, Denise Del Pra Netto; HOFFMANN, Micheline Gaia. Avaliação da percepção de professores da Furb sobre o conceito de inovação e o papel do Nit em uma Universidade. n. 28, julho: Revista Estudos do CEPE. 2008.

MOTA, Teresa Lenice Nogueira da Gama. Interação universidade-empresa na sociedade do conhecimento: reflexões e realidade. Brasília, v. 28, n. 1, Jan. 1999. Disponível em: $<\mathrm{http}$ ://www.scielo.br/scielo.php?script=sci_arttext\&pid=S0100-

19651999000100011\&lng=en\&nrm=iso $>$. Acesso dia 14 Jan. 2013.

NEVES, José Luis. Pesquisa qualitativa, características, usos e possibilidades.

Caderno de pesquisas em administração. São Paulo. v. 1, n. 3. 1996.

ORLANDI, Eni Puccinelli. Análise de discurso: princípios \& procedimentos. 10. ed. Campinas, São Paulo: Pontes, 2012. 
PEREIRA NETO, André; GALLINDO, Fabiano; CRUZ, Santiago Reis da. O programa de apoio à pesquisa em empresas e o Rio Inovação: uma avaliação preliminar. Inteligência empresarial, Rio de Janeiro, v. 1, n. 21, p. 4-12, 2004.

PERKMANN Marcus; KING, Zella, PAVELIN Stephen, Engaging excellence? Effects of faculty quality on industry engagement across disciplines, Research Policy, n. 40, p.539-552, 2011.

RIPPER FILHO, José Ellis. Ciência e tecnologia: para quê? como? In: MUSA, Edson Vaz etal. Ciência e tecnologia: alicerces do desenvolvimento. São Paulo: Cobram, 1994.

ROESCH, Sylvia Maria Azevedo. Projetos de estágio e de pesquisa em administração. 3 . ed. São Paulo: Atlas, 2005.

SCHUMPETER, Joseph Alois. Capitalism, Socialism, and Democracy. New York: Harper. 1942.

SILVA, Anielson Barbosa da; GODOI, Christiane Kleinübing; BANDEIRA-DE-MELLO, Rodrigo. Pesquisa qualidade em estudos organizacionais: paradigmas, estratégias e métodos. São Paulo: Saraiva, 2006.

YIN, Robert K. Estudo de caso: planejamento e métodos. 3. ed. Porto Alegre: Bookman, 2005. 